Research Article

\title{
A community based cross-sectional study to identify individuals at high risk for diabetes in urban slums of Hubli
}

\author{
Anjana P.*, Dattatreya D. Bant
}

Department of Community Medicine, Karnataka Institute of Medical sciences, Hubli, Karnataka, India

Received: 30 October 2015

Revised: 04 November 2015

Accepted: 11 December 2015

\author{
*Correspondence: \\ Dr. Anjana P., \\ E-mail: anjanagraju@gmail.com
}

Copyright: ( $)$ the author(s), publisher and licensee Medip Academy. This is an open-access article distributed under the terms of the Creative Commons Attribution Non-Commercial License, which permits unrestricted non-commercial use, distribution, and reproduction in any medium, provided the original work is properly cited.

\begin{abstract}
Background: India is called as the Diabetes Capital of the world, harbouring nearly 62 million cases. The present study was conducted to identify the individuals at risk for diabetes in the urban slum of Hubli and to assess the risk factors for Diabetes among them.

Methods: It was a Community based cross-sectional study. Multistage sampling was done recruiting 200 adults $>20$ years. They were interviewed using a prestructured questionnaire about risk factors for diabetes followed by the Anthropometry. Chi-square test, t test and multinomial Regression analysis were applied. P value $<0.05$ was considered as statistically significant.

Results: Individuals who are at high risk of diabetes according to Indian Diabetic Risk Score constitutes upto 45\%; followed by $31 \%$ in medium and $24 \%$ in low risk category. $43 \%$ belonged to age group of $20-35$ years, $66 \%$ were leading sedentary lifestyle, $4.5 \%$ have both parents diabetic and $65.5 \%$ are centrally obese. $67 \%$ were having high waist to hip ratio and $71 \%$ were having high waist to height ratio. There was a significant difference in the mean weight and height between the males and females in the study. Age, Sex, Body Mass Index, Positive family History, Physical activity, Blood pressure, Waist score, Waist/Height ratio were significantly associated with the risk categories.

Conclusions: The magnitude of high risk individuals for diabetes in urban slums is high. Regular Screening programs will help in early detection and appropriate intervention to prevent/delay the progression to diabetes and its complications.
\end{abstract}

Keywords: Body mass index, Diabetes mellitus, Obesity, Risk factors, Sedentary lifestyle, Waist-height ratio, Waisthip ratio

\section{INTRODUCTION}

Diabetes Mellitus is a leading cause of death and disability worldwide. Its prevalence was about $8 \%$ in 2011 and its predicted to rise by $10 \%$ by $2030 .{ }^{1}$ The prevalence of diabetes mellitus will almost double in the next 25 years and at least $75 \%$ of those affected will be in developing countries. The burden of disease will be worse in these countries, as the majority of sufferers are expected to be relatively young, of lower socioeconomic status and to suffer from severe disease of premature onset. $^{2}$ It is expected that by 2020 in developing countries, non-communicable diseases (NCDs) will account for $69 \%$ of all deaths, with cardiovascular diseases in the lead. ${ }^{3}$ Of the 57 million deaths that occurred globally in 2008, 36 million were due to NCDs comprising mainly cardiovascular diseases, diabetes, cancers and chronic lung diseases. NCDs, once considered as "diseases of affluence" are now common in low and middle income countries. ${ }^{4}$ 
Type 2 Diabetes mellitus is the most common type of diabetes. It usually occurs in adults but increasingly seen in children and adolescents. In type 2 diabetes, the body is able to produce insulin but either this is not sufficient or the body is unable to respond to its effect (also known as Insulin resistance) leading to a build-up of glucose in blood. Globally 382 million people have diabetes. By 2035, this will rise to 592 million. Greatest number of people with diabetes are between 40 to 59 years of age, 175 million people with diabetes are undiagnosed. About $80 \%$ of people with diabetes live in low and middle income countries The south east Asia region accounts to one-fifths of all adults with diabetes. Current estimates indicate that 72.1 million people have diabetes, of which 65.1 million live in India. The projected Increase in regional prevalence to $10.1 \%$ in 2035 is a consequence of on-going large scale urbanization and increasing life expectancy. In India, the proportion of population over 50 years is expected to increase from $27 \%$ to $35 \%$ between 2013 and 2035. According to the International Diabetes Federation Estimation, India will have a rise in people living with diabetes upto 87.0 million by 2030 from 50.8 million in 2010 making it the Diabetes Capital of the world. ${ }^{6}$

Over the last few decades, traditional societies in many developing countries have experienced rapid and unplanned urbanization, which has led to lifestyles characterized by unhealthy nutrition, reduced physical activity and tobacco consumption. ${ }^{7}$ Modern Lifestyle associated with easy access to food, lack of exercise, sedentary lifestyles, caloric dense foods and excessive watching television contributing to development of NCDs. ${ }^{8}$

Diabetes is one of the major causes of premature illness and death worldwide. The real burden of Diabetes is however due to its micro and macro vascular complications which lead to increased morbidity and mortality and loss of productivity and foregone economic growth. ${ }^{9}$ Diabetes was defined as individuals diagnosed by a physician and on glucose-lowering medications (self-reported) and/or those who had a fasting $\mathrm{CBG} \geq 7$ $\mathrm{mmol} / \mathrm{l}(\geq 126 \mathrm{mg} / \mathrm{dl})$ and/or a $2 \mathrm{~h}$ post glucose CBG value $\geq 12.2 \mathrm{mmol} / 1(\geq 220 \mathrm{mg} / \mathrm{dl}){ }^{10}$

There are several potential strategies for diabetes screening the purpose of which is to identify asymptomatic individuals, in whom the screening can modify the course and complications of the disease. Community screening also enhances public awareness of the seriousness of the diabetes. The Indian Diabetes Risk Score (IDRS) was developed by $\mathrm{V}$ Mohan and his colleagues and is considered to be one of the strongest predictor of incident diabetes in India. ${ }^{11}$ The rapid urbanization, industrialization and economic transition of developing countries is giving rise to birth of urban slums. The urban slums are a hub of many communicable diseases, however they are not free from Non communicable disease like diabetes as well the information regarding the identification of high risk individuals and distribution of risk factors for diabetes in urban slums is scarce. Hence this study was conducted with the following objectives to identify the Individuals at high risk for diabetes and to study the profile of risk factors and its association with risk categories among the study sample residing in urban slum of Hubli.

\section{METHODS}

A Community based Cross-sectional study was conducted during December 2014 to January 2015 among the individuals aged more than 20 years who are residents of urban slum area of Old Hubli .Considering the prevalence of Undiagnosed Diabetes in the community as $50 \%$, and a desirable error of $15 \%$ at $95 \%$ confidence interval, the sample size comes to 178 . Attributing $10 \%$ to non-response rate, it comes to 196 which is approximated to 200. Out of 4 wards present in old Hubli area, ward no 42 was selected randomly by Lottery method. Then in this Ward, there are 3 Anganwadis covering the population of this ward. In the next stage, One of the Anganwadi was selected randomly that caters to Assar Oni, Assar Mohalla and Diddi Oni. Finally the study subjects were selected from each area as per population probability proportional to the area i.e., 70 , 70 and 60 respectively. House to House survey was done to interview the individuals and perform Anthropometric measurements such as Weight, Height, Waist circumference, Hip circumference to calculate the required ratios.

After obtaining the Informed consent from the willing participants, they were interviewed using a predesigned questionnaire that consisted details on socio-demographic characteristics, Diet, Habits, Physical exercise, Other risk-factors along with Anthropometry and evaluating the individuals using the Indian Diabetic Risk score for categorizing the subjects. Exclusion Criteria - Patients with history of ischemic heart disease, Diagnosed diabetics, renal and hepatic disease, hypothyroidism and hyperthyroidism, recent surgery/major trauma and patients on Long-term medications for any of the above conditions, Pregnant and Lactating women upto 12 weeks were excluded from the study

Indian Diabetic Risk Score devised by Dr. Mohan and his colleagues of Madras Diabetes research foundation was used which is a simplified risk score for identifying undiagnosed diabetic subjects using four simple parameters - age, waist circumference, family history of diabetes and physical activity. The individuals were classified as having high risk (score $>60$ ), moderate risk (score $30-50$ ) and low risk (score <30) out of total score of $100^{11,12}$ which is shown in the [Table 1]. 
Table 1: MDRF -Indian Diabetic Risk Score. ${ }^{11,12}$

\begin{tabular}{|c|c|c|}
\hline $\begin{array}{l}\text { Categorised Risk } \\
\text { Factors }\end{array}$ & & Score \\
\hline \multirow{3}{*}{ Anora } & $<35$ Years & 0 \\
\hline & $35-49$ years & 20 \\
\hline & $>50$ years & 30 \\
\hline \multirow{3}{*}{$\begin{array}{l}\text { Abdominal obesity } \\
\text { (Waist circumfer- } \\
\text { ence) }\end{array}$} & $\begin{array}{l}\text { Female }<80 \mathrm{~cm} \text {, } \\
\text { Male }<90 \mathrm{~cm} \\
\text { (Reference) }\end{array}$ & 0 \\
\hline & $\begin{array}{l}\text { Female } 80-89 \\
\mathrm{~cm} \text {, } \\
\text { Male } 90-99 \mathrm{~cm}\end{array}$ & 10 \\
\hline & $\begin{array}{l}\text { Female } \geq 90 \mathrm{~cm}, \\
\text { Male } \geq 100 \mathrm{~cm}\end{array}$ & 20 \\
\hline \multirow{4}{*}{ Physical activity } & $\begin{array}{l}\text { Vigorous } \\
\text { exercise or } \\
\text { strenuous at } \\
\text { work }\end{array}$ & 0 \\
\hline & $\begin{array}{l}\text { Moderate } \\
\text { exercise } \\
\text { at work/home }\end{array}$ & 10 \\
\hline & $\begin{array}{l}\text { Mild exercise at } \\
\text { work/home }\end{array}$ & 20 \\
\hline & $\begin{array}{l}\text { No exercise and } \\
\text { sedentary at } \\
\text { work/home }\end{array}$ & 30 \\
\hline \multirow{4}{*}{ Family history } & $\begin{array}{l}\text { Two } \\
\text { non-diabetic } \\
\text { parents }\end{array}$ & 0 \\
\hline & $\begin{array}{l}\text { Either parent } \\
\text { diabetic }\end{array}$ & 10 \\
\hline & $\begin{array}{l}\text { Both parents } \\
\text { diabetic }\end{array}$ & 20 \\
\hline & Maximum Score & 100 \\
\hline
\end{tabular}

\section{RESULTS}

Out of 200, $139(30 \%)$ were females and $61(70 \%)$ were males. 129 were hindus and 71 were muslims. 53 (26.5\%) were illiterate and $74(38 \%)$ were high school passed and above. Majority of them $93(46.5 \%)$ are unemployed category. $112(56 \%)$ of the subjects belong to class IV according to modified B.G. Prasad classification. 91 (45\%) of the subjects belong to high risk category, followed by medium and low risk category depicted in Figure 1.

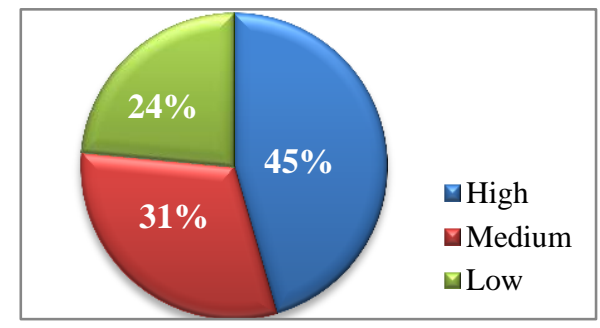

Figure 1: Distribution of study sample according to Indian Diabetic Risk Score.
$43 \%$ are in the age group of $20-35$ years, $66 \%$ leading sedentary lifestyle, $4.5 \%$ have both parents diabetic and $65.5 \%$ are centrally obese. $88(44 \%)$ were obese, 58 (29\%) were normal followed by 42 (21\%) were overweight and $6 \%$ were underweight. $67 \%$ were having high waist to hip ratio. $71 \%$ were having high waist to height ratio. $11 \%$ of males were currently smoking and $12 \%$ were currently consuming alcohol. Distribution of the components of IDRS in the study sample is shown in the Figure 2.

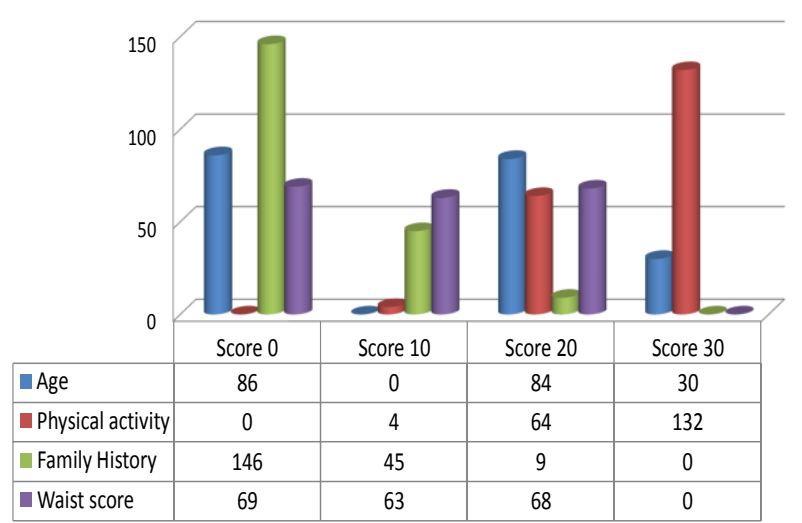

Figure 2: Distribution of IDRS components among the study sample.

There was a significant difference in the mean weight and height between the males and females in the study, however waist circumference, body mass index , waist/hip ratio did not show any significant difference in their means between sexes on Independent $t$ test. On Chi square analysis, age, Sex, Body Mass Index, Positive family History, Physical activity, Blood pressure, Waist score, Waist/Height ratio were significantly associated with the risk categories whereas Socioeconomic status, Religion, Educational Status, type of diet, type of cooking oil used did not show any Significant association. Subjecting the variables that showed association on chi-square analysis to multinomial Logistic regression analysis, between low risk group with moderate risk and high risk category. When Low risk group is compared with Moderate risk group, Individuals having high waist to Hip ratio and Waist to Height ratio have an odds of 3.095 and 3.938 respectively to be in the Moderate risk category shown in (Table 2). The comparison between the low risk with high risk group is shown in [Table 3], where in female sex, sedentary lifestyle, high waist hip ratio and waist to height ratio have higher odds of $3.569,9.004,6.415$ and 11.717 respectively to be in the high risk category. 
Table 2: Multinomial Regression analysis on comparing the low risk IDRS group with Moderate risk group.

\begin{tabular}{|c|c|c|c|c|}
\hline Variable & $\begin{array}{l}\text { Beta } \\
\text { coefficient }\end{array}$ & Odds Ratio & $95 \%$ CI limits of OR & Inference \\
\hline $\begin{array}{l}\text { Family history } \\
\text { - No } \\
\text { - } \quad \text { Yes (Ref) }\end{array}$ & -2.773 & 0.062 & $0.008-0.491$ & $\begin{array}{l}\text { P-value } 0.008 \\
\text { Significant }\end{array}$ \\
\hline $\begin{array}{l}\text { Waist to hip ratio } \\
\text { - High } \\
\text { - Normal (Ref) }\end{array}$ & 1.130 & 3.095 & $1.406-6.814$ & $\begin{array}{l}\text { P-value } 0.005 \\
\text { Significant }\end{array}$ \\
\hline $\begin{array}{l}\text { Waist to height ratio } \\
\text { - High } \\
\text { - Normal (Ref) }\end{array}$ & 1.37 & 3.938 & $1.762-8.801$ & $\begin{array}{l}\text { P-value } 0.001 \\
\text { Significant }\end{array}$ \\
\hline
\end{tabular}

Table no 3: Multinomial Regression analysis on comparing the low risk IDRS group with High Risk group.

\begin{tabular}{|c|c|c|c|c|}
\hline Variable & $\begin{array}{l}\text { Beta } \\
\text { coefficient }\end{array}$ & Odds Ratio & $\begin{array}{l}95 \% \text { CI limits of } \\
\text { OR }\end{array}$ & Inference \\
\hline $\begin{array}{ll}\text { Sex } & \\
\text { - } & \text { Females } \\
\text { - } & \text { Males (Ref) }\end{array}$ & 1.272 & 3.569 & $1.651-7.715$ & $\begin{array}{l}\text { P: } 0.001 \\
\text { Significant }\end{array}$ \\
\hline $\begin{array}{l}\text { Sedentary Lifestyle } \\
\qquad \quad \text { Sedentary } \\
\text { - } \quad \text { Nonsedentary (Ref) }\end{array}$ & 2.198 & 9.004 & $3.836-21.314$ & $\begin{array}{l}\text { P: } 0.000 \\
\text { Significant }\end{array}$ \\
\hline $\begin{aligned} & \text { BMI } \\
& \text { - Normal } \\
& \text { - Above Normal (Ref) }\end{aligned}$ & -0.879 & 0.415 & $0.193-0.892$ & $\begin{array}{l}\text { P: } 0.001 \\
\text { Significant }\end{array}$ \\
\hline $\begin{array}{l}\text { Family History } \\
\qquad \quad \text { No } \\
\qquad \quad \text { Yes (Ref) }\end{array}$ & -3.451 & 0.032 & $0.004-0.240$ & $\begin{array}{l}\text { P value: } 0.001 \\
\text { Significant }\end{array}$ \\
\hline $\begin{array}{l}\text { Waist to Hip ratio } \\
\qquad \quad \text { High } \\
\text { - } \quad \text { Normal ( Ref) }\end{array}$ & 1.859 & 6.415 & 2.924 & $\begin{array}{l}\mathrm{P}: 0.000 \\
\text { Significant }\end{array}$ \\
\hline $\begin{array}{l}\text { Waist to Height Ratio } \\
\text { - } \quad \text { High } \\
\text { - } \quad \text { Normal (Ref) }\end{array}$ & 2.461 & 11.717 & $4.948-27.746$ & $\begin{array}{l}\text { P:0.000 } \\
\text { Significant }\end{array}$ \\
\hline
\end{tabular}

\section{DISCUSSION}

In a study by Chowdhury Ranadip et al $43.4 \%$ were males and $56.6 \%$ were females. ${ }^{13}$ Similarly in this study females constituted more than males. In a study on diabetes, obesity and dyslipidemia in urban slums conducted by A Misra et al there was preponderance of Hindu Population followed by Muslims and Christians which is similar to this study. ${ }^{14}$ A study by Tusshar Acharyya et al showed $17 \%$ of males and $51 \%$ of females were illiterate, similar to the findings of this study where in, out of $26.5 \%$ of Illiteracy, 92\% Females and 14\% males were Illiterate in this study. ${ }^{15}$ In a study by Chythra $\mathrm{R}$ Rao et al $53.6 \%$ were housewives. ${ }^{16}$ Similarly in this study, out of $46.5 \%$ Unemployed, 85 females $(59.1 \%)$ are housewives. In a study by Chowdhury Ranadip et al $22.6 \%$ of the population belonged to Upper Lower class of B.G Modified Prasad Classification. ${ }^{13}$ However in this study, $56 \%$ of the study sample belonged to upper lower class. In study by Chowdhury Ranadip et al, $31.5 \%$ are high risk IDRS category followed by $46 \%$ belonging moderate risk and $22.5 \%$ are low risk category. ${ }^{13}$ In our study $45.5 \%$ people belonged high risk, $31 \%$ belonged middle risk and $23.5 \%$ belonged low risk. In a study by Tushar Acharyya et al $36 \%$ had BMI $23-27.4 \mathrm{~kg} / \mathrm{m}^{2}$ and in $10.9 \%$ had BMI $>27.5 \mathrm{~kg} / \mathrm{m}^{2} .{ }^{15}$ In this study $21 \%$ belong to Overweight category of BMI $23-24.9 \mathrm{Kg} / \mathrm{m}^{2}$ and $44 \%$ belong to obese category with BMI $>25 \mathrm{Kg} / \mathrm{m}^{2}$. In a study by Chythra $\mathrm{R}$ Rao et al in rural population, majority of males 
had normal waist to hip ratio and $92.7 \%$ females had high ratio similar to this study where $76.95 \%$ females and only $14.175 \%$ males have high ratio. ${ }^{16}$

In a study conducted by Chowdhury Ranadip et al on Multinomial Logistic Regression analysis, when low risk was compared with Moderate risk and severe risk female sex, BMI > 27.5\% and presence of hypertension were found to be more likely to be going in for moderate and high risk respectively which is found statistically significant. ${ }^{13}$ Whereas in this study, when Low risk was compared with moderate and high risk category family history, waist to hip and waist to height ratio were found statistically significant for both set of comparisons. ${ }^{13}$ When low risk was compared with high risk, females were more likely to have more chance in being in high risk category than males and sedentary lifestyle, obese individuals are more likely to be in high risk category compared to non-sedentary and normal BMI persons. And these were found statistically significant.

\section{CONCLUSION}

This study showed that nearly half of the study sample i.e., $45.5 \%$ belong high risk category according to IDRS scale, $25.5 \%$ of them belonging to $36-50$ years age group, followed by medium risk category being $31 \%$ and low risk category $23.5 \%$. Age, Sex, family History, physical activity, waist circumference, waist to height ratio, BMI and $\mathrm{BP}$ were found associated with the severity of the risk for diabetes that is found statistically significant. Regular Health Education and Awareness raising programs regarding adoption of healthy lifestyles is necessary. The IDRS is a simple yet an efficient tool that can be used by the grass root level workers to screen the high risk people and refer to appropriate centres for early detection and appropriate treatment. Urban slums are the vulnerable areas hit by the epidemiological transition seeking more attention with respect to Noncommunicable diseases because of changing lifestyles. Promotion of Regular Physical Exercise by making available of a park or space earmarked for recreational activities, exercises, walk/jogging in the vicinity to this slum along with motivation of the people will help in preventing the development or progress of the disease. Advice and advocate certain stress relaxation techniques which have been found effective like yoga, meditation, pranayama. Frequent and regular school health education programmes to help children develop health promoting behaviour. Subjecting the high risk and moderate risk Individuals for oral glucose tolerance test would have been considered that would further help in confirmation of the status.

\section{ACKNOWLEDGEMENTS}

I would like to thank the Staff of Department of Community Medicine who were the constant source of support. I also extend my gratitude to the Anganwadi teacher and helper of the selected areas of Old Hubli who helped me in providing me the necessary details for the recruitment of subjects. I also thank the Study participants who involved in this study for their Cooperation throughout the study period.

Funding: No funding sources

Conflict of interest: None declared

Ethical approval: The study was approved by the Institutional Ethics Committee

\section{REFERENCES}

1. Akter S, Rahman MM, Abe SK, Sultana P. Prevalence of diabetes and prediabetes and their risk factors among Bangladeshi adults: A nationwide survey. Bull World Health organ. 2014;92:204-13A.

2. Reddy KS, Yusuf S. Emerging epidemic of cardiovascular disease in developing countries. Circulation. 1998;97:596-601.

3. Boutayeb A, Boutayeb S. The burden of noncommunicable diseases in developing countries. Int J Equity Health. 2005;4:2.

4. Deepa M, Pradeepa R, Anjana RM, Mohan V. Non communicable Diseases Risk factor Surveillance: Experience and challenge from India. Indian $\mathbf{J}$ Community Med. 2011;36(1):S50-6.

5. International diabetes federation (IDF). Country estimates table, 2011. IDF diabetes atlas, 6th edition 2012 .

Available

at http://www.idf.org/sites/default/files/EN_6E_Atlas_ Full_0.pdf. Accessed 4 June 2015.

6. IDF Diabetes Atlas, 4th Edition. International Diabetes Federation, 2009. Available at https://www.idf.org/sites/default/files/IDF-DiabetesAtlas-4th-edition.pdf. Accessed 4 June 2015

7. Reddy KS. Cardiovascular diseases in the developing countries: dimensions, determinants, dynamics and directions for public health action. Public Health Nutr. 2001;5:231-7.

8. Jayamani V, Gopichandran V, Lee P, Alexander G, Christopher S, Prasad JH. Diet and Physical activity among women in urban and rural areas in South India: A Community Based Comparative Survey. J Family Med Prim Care. 2013; 2(4):334-8.

9. Patil RS, Gothankar JS. Prevalence of Type 2 Diabetes Mellitus and associated risk factors in an urban slum of Pune city, India. Natl J Med Res. 2013;3(4):346-9.

10. World Health Organization. Definition and diagnosis of diabetes mellitus and intermediate hyperglycemia: Report of a WHO/IDF Consultation, Geneva. World Health Organization. 2006:39.

11. Mohan V, Deepa R, Deepa M, Somannavar S, Datta M. A simplified Indian diabetes risk score for screening for undiagnosed diabeteic subjects. J Assoc Physicians India. 2005;53:759-63.

12. Mohan V, Sandeep S, Deepa M, Gokulakrishnan K, Datta M, Deepa R. A diabetes risk score helps identify metabolic syndrome and cardiovascular risk in Indians-The Chennai urban rural epidemiology 
study (CURES-38). Diabetes Obes Metab. 2007;9:337-43.

13. Chowdhury R, Mukherjee A, Lahiri SK. A Study on Distribution and determinants of Indian Diabetic Risk Score (IDRS) among rural population of West Bengal. Natl J Med Res. 2012;2(3):282-6.

14. Misra A, Pandey RM, Devi JR, Sharma R, Vikram NK, Khanna N. High Prevalence of diabetes, Obesity and dyslipidaemia in urban slum population in Northern India. Int J Obes. 2001;25:1722-9.

15. Acharyya T, Kaur P, Murhekar M. Prevalence of Behavioural Risk factors, Overweight and Hypertension in the Urban slums of North 24
Parganas District, Westbengal, India, 2010. Indian J Public Health. 2014;58(3):195-8.

16. Rao CR, Kulkarni MM, Narayanan SS, Kamath VG, Kamath A, Ballala K, Sujatha K. Utility of Indian Diabetic Risk Score (IDRS) in a rural area of coastal Karnataka, India. Journal of Evolution of Medical and dental sciences 2014; 3(13):3272-7.

Cite this article as: Anjana P, Bant DD. A community based cross-sectional study to identify individuals at high risk for diabetes in urban slums of Hubli. Int J Community Med Public Health 2016;3:212-7. 